\title{
How physician executives and clinicians perceive ethical issues in Saudi Arabian hospitals
}

\author{
Khalid Saad Bin Saeed King Saud University, Riyadh, Saudi Arabia
}

\begin{abstract}
Objectives-To compare the perceptions of physician executives and clinicians regarding ethical issues in Saudi Arabian hospitals and the attributes that might lead to the existence of these ethical issues. Design-Self-completion questionnaire administered from February to fuly 1997.
\end{abstract}

Setting-Different health regions in the Kingdom of Saudi Arabia.

Participants-Random sample of 457 physicians (317 clinicians and 140 physician executives) from several hospitals in various regions across the kingdom.

Results-There were statistically significant differences in the perceptions of physician executives and clinicians regarding the existence of various ethical issues in their hospitals. The vast majority of physician executives did not perceive that seven of the eight issues addressed by the study were ethical concerns in their hospitals. However, the majority of the clinicians perceived that six of the same eight issues were ethical considerations in their hospitals. Statistically significant differences in the perceptions of physician executives and clinicians were observed in only three out of eight attributes that might possibly lead to the existence of ethical issues. The most significant attribute that was perceived to result in ethical issues was that of hospitals having a multinational staff.

Conclusion-The study calls for the formulation of a code of ethics that will address specifically the physicians who work in the kingdom of Saudi Arabia. As a more immediate initiative, it is recommended that seminars and workshops be conducted to provide physicians with an opportunity to discuss the ethical dilemmas they face in their medical practice.

(Fournal of Medical Ethics 1999;25:51-56)

Keywords: Clinical ethics; physician executives; clinicians; attributes; Saudi Arabia

\section{Introduction}

The practice of medicine and the provision of health care have typically been characterised by ethical concerns. In fact, ethics as applied to medical practice dates back to the ancient civilisations, as we see from the Hippocratic Oath. ${ }^{1}$ However, recent times have witnessed a dramatic increase in the attention paid to ethical issues in the health care sector, particularly issues that concern prioritising medical care and moral decision making. ${ }^{2}$ Ethical challenges in health care have grown mainly because of increasing cost concerns and technological developments, coupled with scientific discoveries that provide professionals with sophisticated medical equipment and unparalleled control over life and death. ${ }^{1}$

The increasing interest in ethical issues has resulted in the conduct of extensive studies relating to medical ethics. Most studies were done in Western settings and there is still a dearth of studies that deal specifically with the realities of the Kingdom of Saudi Arabia's system. However, two recent studies are worth noting. One deals with the attitudes of physicians in Saudi Arabia with regard to communication with terminally ill patients. $^{3}$

The second study analyzed the perceptions of physicians on seven ethical issues in Saudi hospitals. ${ }^{4}$ The latter used the physicians' nationalities (Saudi $\mathrm{v}$ non-Saudi), length of medical practice (less than five years $v$ five years or more) and educational qualification (baccalaureate $\mathrm{v}$ graduate degree) in comparing their perceptions. This study found most statistically significant differences in the perceptions of physicians when their nationalities and length of medical practice were compared.

Physician executives belong to a general category of managers whose traditional relationship with clinicians is said to have been characterised by tension. ${ }^{5}$ This is brought about by the inherent differences in the focus of responsibilities among clinicians and physician executives. Clinicians rightly contend that their fundamental obligation is to provide the best appropriate care for their patients. On the other hand, physician executives 
are responsible both for the patients and for making the best use of resources.

To determine if the traditional differences of clinicians and managers (physician executives) extend to how they perceive ethical issues, this study was conducted with the following specific objectives:

(1) to compare the perceptions of physician executives and clinicians in the Kingdom of Saudi Arabia with regard to ethical issues facing their hospitals; and

(2) to compare the perceptions of physician executives and clinicians in the Kingdom of Saudi Arabia with regard to the attributes that lead to the existence of ethical issues in their hospitals. The current study picks up from earlier research ${ }^{4}$ but addresses a different set of ethical issues and focuses on comparing the perceptions of physician executives and clinicians. Furthermore, the earlier study focused on only one geographical area (Central Region), while the current study gathered data from several regions of the Kingdom of Saudi Arabia and also had more respondents than the said earlier study.

\section{Subjects and methods}

Data were collected from February to July 1997 through the use of self-administered questionnaires. Respondents were randomly selected physician executives and clinicians working in several hospitals from various parts of the Kingdom of Saudi Arabia. On a scale of one to four (1 = strongly agree; $2=$ agree; $3=$ disagree; $4=$ strongly disagree), the respondents were asked to rank their perceptions regarding the extent to which they considered the various issues to be of ethical importance in their hospitals. The respondents were also asked to indicate if they perceived that the attributes specified in the study led to the existence of ethical issues in their hospitals. The respondents were assured of the confidentiality of their answers since they were not asked to provide any specific information that might identify them.

A total of 875 questionnaires were distributed but only 457 were answered completely and included for analysis. Others were discarded due to high rates of missing responses. Therefore, the response rate was $52.2 \%$. Out of the 457 respondents, $140(30.63 \%)$ were physician executives and $317(69.37 \%)$ were clinicians. All of the physician executives and the majority $(63 \%)$ of the clinician respondents were Saudis. Physician executives were physicians who held administrative positions, such as chief executive officer, chief of medical staff and head of clinical departmenţ while also engaged in medical practice. On the other hand, clinicians were those physicians who did not have any administrative work and were solely occupied in medical practice.

Data were analyzed using descriptive statistic (frequency distribution and percentages) and the $\chi$-square test. The latter was utilised to determine if there were statistically significant differences $i \vec{p}$ the perceptions of respondents regarding the vari ous issues and attributes. Statistical differences if the respondents' perceptions were determined significance level $\mathrm{p}<0.05$ for all issues an attributes. The Cramer's V was used to denote the strength of the influence of the respondents' jo on their perceptions.

\section{Results}

PERCEPTIONS OF THE EXISTENCE OF ETHICAL ISSUES Table 1 shows the respondents' perceptions (agre or disagree) and statistical inferences of the differe ent clinical ethical issues considered in this studyo It can be seen from the table that there were sta 0 tistically significant differences in the perceptions of physician executives and the clinicians on $\mathrm{a}$ issues. The vast majority of the physicias executives disagreed that seven of the issues wero ethical considerations in their hospitals. On th other hand, the majority of the clinicians agreed that six of the eight issues were ethical concerns in their hospitals.

With regard to "providing favours to specia patients", "disclosing confidential patient medica information" and "discontinuing medical treaț̣ ment for terminally ill patients", the vast majorit of physician executives disagreed that these were ethical concerns in their hospitals. On the othe? hand, the vast majority of clinicians had the opposite perception on all three issues. The Cramer's values indicate that the respondents' job (whethes physician executive or clinician) had a high influ․ㅡㄹ ence on their perceptions.

All of the physician executives disagreed that "some clinicians receive gifts from patients of their families for providing favourable treatments and "issuing false medical reports to individuals due to social pressures and favoritism" were ethi cal concerns in their hospitals. However, clinician\$ did not have the same unanimous perception. For both issues, the respondents' job was also found to have a high impact on their perceptions regarding the existence of these ethical issues in their hospi $\mathbb{Q}$ tals.

Concerning the issue of "discriminating bee tween patients due to social status, nationality 0 gender," more than three-quarters $(77.9 \%)$ of physician executives disagreed that this was ap 
Table 1 Frequency distribution and statistical inference of respondents'perception of the ethical issues facing the medical professionals working in Saudi hospitals

\begin{tabular}{|c|c|c|c|c|c|c|c|}
\hline \multirow[b]{2}{*}{ Ethical issue } & \multicolumn{2}{|c|}{ Physician executives } & \multicolumn{2}{|l|}{ Clinicians } & \multicolumn{3}{|c|}{ Statistical inference } \\
\hline & $\begin{array}{l}\text { Agree } \\
n(\%)\end{array}$ & $\begin{array}{l}\text { Disagree } \\
n(\%)\end{array}$ & $\begin{array}{l}\text { Agree } \\
n(\%)\end{array}$ & $\begin{array}{l}\text { Disagree } \\
n(\%)\end{array}$ & $\chi$-square & Cramer's $V$ & P-value \\
\hline $\begin{array}{l}\text { Providing favours to special patients such as } \\
\text { private rooms or early appointment }\end{array}$ & $1(0.7)$ & $139(99.3)$ & $265(83.6)$ & $52(16.4)$ & 274.23 & 0.78 & $0.001^{2}$ \\
\hline $\begin{array}{l}\text { Disclosure of patient confidential medical } \\
\text { information }\end{array}$ & $11(7.9)$ & $129(92.1)$ & $253(79.8)$ & $64(20.2)$ & 206.09 & 0.67 & $0.001^{2}$ \\
\hline $\begin{array}{l}\text { Discontinuing medical treatment for } \\
\text { terminally ill patients }\end{array}$ & $26(18.6)$ & $114(81.4)$ & $246(77.6)$ & $71(22.4)$ & 140.45 & 0.55 & $0.001^{\mathrm{a}}$ \\
\hline $\begin{array}{l}\text { Some clinicians receive gifts from patients } \\
\text { or their families for providing favourable } \\
\text { treatments }\end{array}$ & $0(0.0)$ & $140(100.0)$ & $135(42.6)$ & $182(57.4)$ & 84.62 & 0.43 & $0.001^{\mathrm{a}}$ \\
\hline $\begin{array}{l}\text { Issuing false medical reports to individuals } \\
\text { due to social pressures and favouritism }\end{array}$ & $0(0.0)$ & $140(100.0)$ & $133(42.0)$ & $184(58.0)$ & 82.85 & 0.43 & $0.001^{\mathrm{a}}$ \\
\hline $\begin{array}{l}\text { Discriminating between patients due to } \\
\text { social status, nationality or gender }\end{array}$ & $31(22.1)$ & $109(77.9)$ & $211(66.6)$ & $106(33.4)$ & 76.91 & 0.41 & $0.001^{\mathrm{a}}$ \\
\hline $\begin{array}{l}\text { The physicians are unsympathetic to the } \\
\text { cultural and social norms of the patients }\end{array}$ & $50(35.7)$ & $90(64.3)$ & $181(57.1)$ & $136(42.9)$ & 17.76 & 0.20 & $0.001^{\mathrm{a}}$ \\
\hline $\begin{array}{l}\text { Physicians are inattentive to the medical } \\
\text { needs of their patients }\end{array}$ & $72(51.4)$ & $68(48.6)$ & $220(69.4)$ & $97(30.6)$ & 13.60 & 0.17 & $0.001^{\mathrm{a}}$ \\
\hline
\end{tabular}

$\mathrm{a}=$ statistically significant.

ethical consideration in their hospitals. On the other hand, two-thirds $(66.6 \%)$ of the clinicians had the opposite perception. As shown by the Cramer's V value, the respondents' job also had a high influence on their perceptions concerning the existence of this ethical issue in their hospitals.

The majority $(64.3 \%)$ of the physician executives disagreed that "physicians are unsympathetic to the cultural and social norms of the patients" was an ethical issue in their hospitals. However, $57.1 \%$ of the clinicians indicated that this was an ethical concern. Physician executives were basically divided in their perceptions regarding the issue "physicians are inattentive to the medical needs of their patients" (51.4\% agreed and $48.6 \%$ disagreed). On the other hand, the majority $(69.4 \%)$ of the clinicians indicated that this was an ethical issue in their hospitals. The respondents' job was found to have a weak relationship with their perceptions on both issues.

PERCEPTIONS OF THE ATTRIBUTES INFLUENCING THE EXISTENCE OF ETHICAL ISSUES

The respondents' perceptions and statistical inferences of the different attributes that led to the existence of ethical issues are presented in table 2 . It can be seen from the table that the differences in the respondents' perceptions regarding the effect of the various attributes were not as strong as the differences in their perceptions about the ethical issues.

The differences in the perceptions of physician executives and clinicians were statistically significant only on three attributes: "hospital has a multinational staff"; "some clinicians strongly adhere to their concept of clinical autonomy"; and "hos- pital management does not facilitate the conduct of seminars and workshops concerning ethical issues". Regarding multinational staff, the physician executives were equally divided in their perceptions that this attribute led to the existence of ethical issues in their hospitals. However, $77.9 \%$ of the clinicians perceived that the existence of ethical issues was caused by the hospital having a multinational staff. The respondents' job had a moderate influence on their perceptions as to the possible effect of a multinational staff on the existence of ethical issues.

The majority $(67.1 \%)$ of the physician executives did not agree that the attribute "some clinicians strongly adhere to their concept of clinical autonomy" led to the existence of ethical issues. This perception was shared by $52.1 \%$ of clinicians. With regards to the attribute "hospital management does not facilitate the conduct of seminars and workshops concerning ethical issues", $55 \%$ of physician executives and $68.5 \%$ of clinicians perceived that this led to the existence of ethical concerns in their hospitals. The Cramer's $\mathrm{V}$ values indicate that there were weak relationships between the respondents' job and their perceptions as to the influence of both attributes on the existence of ethical issues in their hospitals.

There was no statistically significant difference in the perceptions of physician executives and clinicians about the influence of the five other attributes on the existence of ethical issues in their hospitals. These attributes were:

(1) "lack of committee to investigate ethical issues";

(2) "lack of technical follow-up to monitor physicians' medical practices"; 


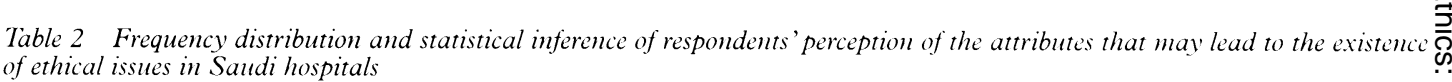

\begin{tabular}{|c|c|c|c|c|c|c|c|}
\hline \multirow[b]{2}{*}{ Attributi } & \multicolumn{2}{|c|}{ Phasician ciecutices } & \multicolumn{2}{|l|}{ Climiciams } & \multicolumn{3}{|c|}{ Statistical infirencio } \\
\hline & Yes $n\left({ }^{\prime \prime}(1)\right.$ & $\operatorname{Non}\left({ }^{\circ}{ }^{\prime}\right)$ & $\operatorname{Yes} n(" 1)$ & Non (" & $1-s q u a t i$ & Cramlers 1 & $P-i u l=$ \\
\hline Hospital has a multinational staff & $70(50.0)$ & $70(50.0)$ & $247(77.9)$ & $70(22.1)$ & 35.62 & 0.28 & 0.001 \\
\hline $\begin{array}{l}\text { Some physicians strongly adhere to their } \\
\text { concept of clinical autonomy }\end{array}$ & $46(32.9)$ & $9+(67.1)$ & $152(48.0)$ & $165(52.1)$ & 9.01 & $0.1+4$ & $0.0033^{0}$ \\
\hline $\begin{array}{l}\text { Hospital management does not facilitate the } \\
\text { conduct of seminars and workshops }\end{array}$ & & & & & & & \\
\hline concerning ethical issues & $77(55.0)$ & $63(45.0)$ & $217(68.5)$ & $100(31.6)$ & 7.66 & 0.13 & 0.000 \\
\hline Lack of committee to investigate ethical issues & $71(50.7)$ & $69(49.3)$ & $138(+3.5)$ & $179(56.5)$ & 2.02 & -0.07 & 0.155 \\
\hline $\begin{array}{l}\text { Lack of technical follow-up to monitor } \\
\text { physicians' medical practices }\end{array}$ & $60(42.9)$ & $80(57.1)$ & $115(36.3)$ & $202(63.7)$ & 1.78 & -0.06 & 0.182 \\
\hline $\begin{array}{l}\text { Hospital by-laws do not emphasise medical } \\
\text { code of ethics }\end{array}$ & $88(62.9)$ & $52(37.1)$ & $178(56.2)$ & $139(43.9)$ & 1.80 & -0.06 & 0.1800 \\
\hline $\begin{array}{l}\text { Patients' rights and duties are not specified in } \\
\text { the hospital operating manual }\end{array}$ & $64(45.7)$ & $76(54.3)$ & $162(51.1)$ & $155(48.9)$ & 1.13 & 0.05 & 0.288 \\
\hline $\begin{array}{l}\text { Lack of punitive measures against those who } \\
\text { do not abide by the accepted standards of } \\
\text { medical practice }\end{array}$ & $62(44.3)$ & $78(55.7)$ & $154(48.6)$ & $163(51.4)$ & 0.72 & 0.04 & 0.397 \\
\hline
\end{tabular}

$\mathrm{a}=$ statistically significant

$\mathrm{ns}=$ not statistically significant

(3) "hospital by-laws do not emphasise medical code of ethics";

(4) "patients' rights and duties are not specified in the hospital operating manual"; and

(5) "lack of punitive measures against those who do not abide by the accepted standards of medical practice".

\section{Discussion}

The results of this study indicate the differences in how physician executives and clinicians look at and see the same situations. However, it should be noted that the executives in this study are also clinicians. Therefore, there maybe more than just "traditional differences" in how they see things, as the perceptions of physician executives and clinicians are almost at the opposite ends of an agree-disagree spectrum. For example, less than $1 \%$ of the physician executives perceived that providing favours to special patients was an ethical concern in their hospitals, but the vast majority of the clinicians had the opposite perception.

The highly significant differences in the perceptions of physician executives and clinicians may also indicate that physician executives may not be willing to admit that the actions or activities of some colleagues are ethically questionable. Or they may indicate that as far as they were concerned, there was nothing ethically wrong in how things were done in their hospitals. On the other hand, clinicians probably saw the situations from a different perspective or looked at them from a purely clinical point of view. Thus, although an action may be "more ethically wrong" from a purely clinical perspective, it may be considered as "more ethically right" if viewe from other dimensions.

Another possible explanation for the difference in the perceptions of the two groups is that phys? cian executives might have combined both ethic thinking and traditional management reasoning i looking at situations. This point of view coulg allow them to see ethical issues as one componerf in the broader context of administrative practice It should be noted that physician administrator have various obligations that may weigh diffe? ently, depending on the particular situation question." They have administrative, financial ang biomedical responsibilities, which may have var ing influence on how they evaluate a specifig circumstance.

For instance, take the issue of discontinuing treatment for terminally ill patients. The vast majority of clinicians might have considered thi an ethical problem because they were more liker than the physician executives to adhere to thif principle of beneficence, which views preservatio of life at all means as the main duty of the physician.' On the other hand, physician execus tives might have considered their obligation to the patient while also weighing their other responsi bilities. Under conditions of scarcity in resources the best course of action for terminally ill patiente might not be treatment but providing care tha will maintain their dignity, while scarce resource $\mathbb{\Phi}$ are channelled to other patients who have betteg chances of survival. Although this may seem an abandonment of physicians' duty of preservatio of life, it is consistent with their duty to society ac흉 a whole. 


\section{Different ethical theories}

The results of this study also indicate that physician executives and clinicians were likely to follow different ethical theories in how they perceived a particular situation. Physician executives seemed more likely to consider a teleological or utilitarian ethics, which is based on the premise that an action is right if it leads to the greatest good. On the other hand, clinicians seemed to have adhered more to a deontological ethics, which considers an action to be right only if it is in accordance with principled moral obligation, and which regards persons as ends in themselves. ${ }^{7}$

Cultural differences are another very challenging issue that should be taken seriously by physicians, especially when they are treating patients with life-threatening conditions. This is extremely important in view of the fact that the Kingdom of Saudi Arabia's system not only has a multinational workforce but also has multinational patients. For example, dealing with a number of cancer patients of different nationalities requires different approaches to both the patients and their families. And in treating Saudi patients, foreign physicians should take into serious consideration the local customs and traditions. However, physicians should never have a conventionalised idea about any particular culture. They should bear in mind that a patient or a family's reaction to a certain situation is a combination of various cultural influences. $^{9}$

Considering the results of this study, it can be inferred that the impact of having a multinational hospital staff on the existence of ethical issues was felt more by clinicians than by physician executives. However, physician executives and clinicians shared common perceptions about the influence of lack of continuing education activities, such as workshops, conferences and seminars and the absence of a code of ethics on the existence of ethical issues. The majority in both groups of respondents believed that these two attributes were important factors that led to the existence of ethical issues. It should be noted that there were no statistically significant differences in the perceptions of the physician executives and clinicians regarding the importance of this attribute in influencing the existence of ethical issues in Saudi hospitals. This means that both groups of respondents recognised the importance of these attributes.

While the Kingdom of Saudi Arabia employs a significant number of foreign physicians of various nationalities, there is no specific code of ethics for doctors working in its vast health care sector. ${ }^{4} \mathrm{~A}$ combination of these two factors, ie significant numbers of foreign physicians and the lack of a specific code of ethics for doctors, can indeed result in serious ethical problems in any setting. Expatriate physicians certainly bring with them diverse cultures and values that may, at times, be in conflict with not only their local counterparts, but also with the cultures and values of their patients. However, the ethical problems arising from the presence of a multinational hospital medical staff may be reduced by introducing a code of ethics that applies specifically to those physicians working in the Kingdom of Saudi Arabia.

\section{Collective values}

Although a code of ethics need not lay down hard and fast rules, it can provide guidance in situations when ethical dilemmas arise. And because a code of ethics reflects the collective values of the profession, it can serve as a point of departure for dealing with ethical dilemmas. ${ }^{10}$ If necessary, the code of ethics can also be used to dismiss somebody who does not comply with standards of acceptable conduct. These codes are usually acceptable not only because they represent the attitude of a profession, but because they contain statements which reflect behaviour acceptable to society in general. ${ }^{11}$

As earlier stated, the respondents also had a consensus with regard to the negative effect of hospitals not encouraging the conduct of seminars and workshops that deal specifically with ethical issues. While professional competence requires technical as well as ethical education, around $90 \%$ of medical curriculum has been traditionally devoted to technical education, resulting in serious neglect of the ethical dimension. ${ }^{12}$ This justifies the conduct of activities that could make up for the lack of emphasis on ethics teaching in the formal education of physicians. This is acknowledged to be very important in a setting where physicians and patients not only share a common cultural heritage but where, also, physicians are guided by a professional code of ethics. How much more important an issue is it, then, in the case of the Kingdom of Saudi Arabia?

This study echoes the call of an earlier one for the formulation of a code of ethics for physicians working in Saudi hospitals. ${ }^{4}$ The author recognises that this may take some time to materialise. It is therefore suggested that, in the short term, a more important initiative may be to conduct educational activities such as workshops and conferences to address the ethical issues that medical professionals have to deal with in our hospitals. Given the realities of the kingdom's health care sector, ie, having a multinational staff which does not have any code of ethics to follow, 
it is imperative that educational activities that deal specifically with ethical realities should be made available to physicians. Such activities can be designed to help them openly share and discuss their experiences of ethical dilemmas in their medical practice.

As in any study that relies mainly on data obtained from self-administered questionnaires, caution should be taken in drawing general conclusions from the results of this study. However, the findings presented here provide an insight into the influence different roles may have on how individuals perceive the same thing.

To obtain a clearer picture of the ethical considerations in our hospitals, it is recommended that further studies be conducted in this area. An ideal, comprehensive study would be one that included the views of both professionals and patients. It is further suggested, that studies be conducted to address different issues using different statistical techniques and/or that a more detailed study of the same issues addressed here be undertaken.

Khalid Saad Bin Saeed, PhD, is currently an Associate Professor, Master's Program in Hospital and Health Administration, College of Administrative Sciences, King Saud University, Riyadh, Saudi Arabia. He obtained a PhD in Health Policy and Administration from the University of North Carolina at Chapel
Hill, USA. He is the immediate past Executive Direc․․․․․․ tor of King Khalid University Hospital, an 800-bed. teaching hospital affiliated to King Saud University College of Medicine. He is a member of the International Society for Quality Assurance.

\section{References}

1 Sauer JE Jr. Ethical problems facing the industry. Hospital $\vec{\theta}$ Health Services Administration 1985;30:44-53.

2 Benner P. The role of experience, narrative, and community $\overrightarrow{t r}$ skilled ethical comportment. Adranced Nursing Science 190 14:-21.

3 Mobeireek Al: Al-Kassimi FA, Al-Majid SA, Al-Shimemry Communication with the seriously ill: physicians' attitudes Saudi Arabia. Fournal of Medical Ethics 1996;22:282-5. O

4 Bin Saced KS, Al-Humedhi A. Physicians' perceptions regard ing the existence of medical ethical issues in Saudi hospitator Accounting, Management, and Insurance Revicas. Cairo: Caire University (in press).

5 Rigbv MJ, Robins SC. Integrated electronic records as the resolution of ethical tensions between clinical and manageriat objectives. MEDINF() 95 Proceedings 1995:280-4.

6 Summers JW. Closing unprofitable services: ethical issues an management responses. Hospital E Health Services Administ tion 1985;30:8-28.

7 Gibson CH. Lnderpinnings of ethical reasoning in nursin fournal of Adianced Nursing 1993;18:2003-7.

8 Garrett TM, Baillie HW, Garrett RM. Health care ethics: princ ples and problems [2nd ed]. Englewood Cliffs, New Jersed Prentice-Hall Inc, 1993.

9 Wright F, Cohen S, Caroselli (.. Diverse decisions: how cultuß affects ethical decision making. Critical Care Nursing Climics North America 1997;9:63-74.

10 Erlen JA. The code for nurses: guidelines for ethical practic Orthopaedic Nursing 1993; 12:31-3, 46.

11 Oglesby DK Jr. Ethics and hospital administration. Hospital $\frac{\text { है }}{\Phi}$ Health Services Administration 1985;30:29-43.

12 Kipnis K. Professional ethics in health carc: an introduction Haciail. Medical fourmal 1990; 49:292-t.

\section{News and notes}

\section{Teaching Research Ethics}

Indiana University's sixth annual Teaching Research Ethics workshop will be held in Bloomington, Indiana, USA from May 26-29, 1999.

Session topics will include: an overview of ethical theory; using animal subjects in research; using human subjects in clinical and non-clinical research, and responsible data management.
For more information please contact: Kenneth D Pimple, Teaching Research Ethics Project Director, Poynter Center, Indiana University, 618 East Third Street, Bloomington IN 47405; tel: (812) 855-0261; fax: 8553315; pimple $(a$ indiana.edu;http://www.indiana.edu/ $\sim$ poynter/index.html 